\title{
Population-based incidence, mortality and quality of life in critically ill patients treated with renal replacement therapy: a nationwide retrospective cohort study in finnish intensive care units
}

Suvi T Vaara ${ }^{1 *}$, Ville Pettilä ${ }^{1}$, Matti Reinikainen ${ }^{2}$ and Kirsi-Maija Kaukonen ${ }^{1}$, for

the Finnish Intensive Care Consortium

\begin{abstract}
Introduction: Acute kidney injury (AKI) increases mortality and morbidity of critically ill patients. Mortality of patients treated with renal replacement therapy (RRT) is high. We aimed to evaluate the nationwide incidence of RRT-treated AKI in Finland, hospital and six-month mortality, and health-related quality of life (HRQoL) of these patients.

Methods: We performed a retrospective cohort study including all general intensive care unit (ICU) admissions in Finland in 2007 through 2008. We identified patients who had received RRT due to AKI (RRT patients) and compared these patients to ICU patients who were not treated with RRT (non-RRT patients). The HRQoL was assessed by the EQ-5D index and visual analogue scale (VAS).

Results: We analysed the final cohort of 24,904 patients, of whom 1,686 received RRT due to AKI. The incidence of RRT-treated AKI was 6.8\% (95\% confidence interval (CI) 6.5 to $7.1 \%$ ) among $\geq 15$-year-old general ICU patients, which corresponds to a yearly population-based incidence of 19.2 per 100,000 (95\% Cl 17.9 to 20.5/100,000). According to RIFLE (Risk, Injury, Failure) classification 26.6\% (95\% Cl 26.0 to 27.2\%) of patients had AKI (RIFLE R-F). Hospital and six-month mortality of RRT patients were $35.0 \%$ and $49.4 \%$. At six-months, RRT patients perceived their health as good as non-RRT patients by VAS.

Conclusions: The population-based incidence of AKI treated with RRT was 19.2 per 100,000 in Finland and 6.8\% of all general ICU patients. The hospital and six-month mortality rates were lower than previously reported for ICUtreated RRT patients.
\end{abstract}

\section{Introduction}

Acute kidney injury (AKI) increases mortality, length of stay (LOS) and resource need in intensive care unit (ICU) patients. The incidence of AKI has been reported to vary between 6 and 70\% among ICU patients depending on the definition [1-3]. The RIFLE (Risk, Injury, Failure) -classification for AKI based on serum creatinine concentration and urine output was published in 2004

\footnotetext{
* Correspondence: suvi.vaara@helsinki.fi

'Intensive Care Units, Division of Anaesthesia and Intensive Care Medicine, Department of Surgery, Helsinki University Central Hospital, Box 340, 00029 HUS, Finland

Full list of author information is available at the end of the article
}

[4]. Patients receiving renal replacement therapy (RRT) represent the most severe form of AKI.

The incidence of RRT-treated AKI in populations has been reported to vary between 8 and 30 per 100,000/ year [5-12] with an increasing trend [11,12]. The incidence of RRT-treated AKI among general ICU patients lies between 4 and $8 \%[1,3,13,14]$. Hospital mortality of these patients has been reported to be 44 to $64 \%$ [5,13,15-19]. Higher disease severity [3], use of vasoactive drugs, mechanical ventilation, sepsis [1] and longer hospital stay prior to ICU ad-mission [17] are associated with increased hospital mortality. Surgical admission is related with better outcome $[17,19]$. Furthermore,

\section{C) Biomed Central}


health-related quality of life (HRQoL) of RRT-treated AKI patients has been reported to be lower than in general population [20]. However, the number of patients in these studies has been limited [6,20,21]. Studies presenting the incidence of RRT-treated AKI in general ICU patients along with long-term outcome and HRQoL are scarce.

Accordingly, we aimed to evaluate the nationwide incidence of RRT-treated AKI in Finland, and their hospital and six-month mortality, and their HRQoL at baseline and after six months follow-up.

\section{Materials and methods}

The board of the Finnish Intensive Care Consortium (FICC) approved the study protocol. The Ethics Committee of the Department of Surgery, Hospital District of Helsinki and Uusimaa waived the need for an informed consent. The consortium maintains a database, where detailed data on patient characteristics, disease severity scores, and patient outcomes are prospectively collected and validated. During the study period from 1 January 2007 to 31 December 2008, the database included all admissions in nine ICUs of five Finnish University hospitals and in 15 central hospitals and included 30,380 ICU admissions. Four highly specialised units were not members of the consortium, but the number of RRT-treatments in these units is minimal. Thus, all general ICUs providing RRT were included in the study.

We searched the database for patients who had received RRT due to AKI. RRT and the day of RRT initia-tion were registered in the database. For comparison, we obtained the same data on all ICU patients for the same period. For all analyses we excluded readmissions, patients under the age of 15, patients with endstage renal disease (ESRD) requiring dialysis prior to ICU admission based on chronic health evaluation, and patients admitted because of drug or alcohol intoxication.

The data of each patient treated in the ICU during the study period included 1) demographic data, 2) SAPS II (Simplified Acute Physiology Score) [22] and SOFA (Sequential Organ Failure Assessment) severity scores and organ spe-cific SOFA scores [23],3) intensity of care measured by TISS (Therapeutic Intervention Scoring System) score [24], 4) APACHE (Acute Physiology and Chronic Health Evaluation) III and ICD-10 (International Classification of Diseases, $10^{\text {th }}$ revision) diagnosis and the APACHE III diagnosis group, 5) physiological data, and 6) laboratory values. In addition to daily creatinine values, we obtained the data of the severity scores as well as physiological and laboratory values from the first 24-hour ICU-treatment period. If data were missing for more than $5 \%$ of cases, we indicate it in the tables. We used the Finnish population data from Statistics Finland for the epidemiological calculations. On 31 December 2007, Finland (except the Åland Islands) had 4,383,358 $\geq 15$-year-old inhabitants. We analysed the data on ICU and hospital length of stay, hospital mortality and six-month mortality. We calculated the standardised mortality ratio (SMR, the number of observed hospital deaths divided by the number of expected deaths) according to the original SAPS II equation [22].

We classified the patients according to the maximum RIFLE class [4] during their ICU stay. Due to missing urine output data we only used the glomerular filtration rate (GFR) criteria: RIFLE-Risk serum creatinine $\geq$ baseline creatinine $\times 1.5$; RIFLE-Injury serum creatinine $\geq$ baseline $\times 2$; RIFLE-Failure serum creatinine $\geq$ baseline $\times 3$ or $>354$ micromol/l with an acute rise $>44$ micro$\mathrm{mol} / \mathrm{l}[4]$. As baseline creatinine we used the lowest value of the follow-ing: the lowest creatinine during the patient's ICU stay (in 76\% of the cases) or calculated creatinine from the MDRD (Mod-ification in Diet in Renal Disease) equation [25] assuming a glomerular filtration rate of $75 \mathrm{ml} /$ minute $/ 1.73 \mathrm{~m}^{2}$ as recom-mended by ADQI (Acute Dialysis Quality Initiative) [4]. We determined the day of RRT initiation and the preceding RIFLE class.

We analysed the HRQoL with the EuroQol (EQ-5D) instrument [26,27]. EQ-5D includes five dimensions: mobility, self-care, usual activities, pain/discomfort and anxiety/depression. Each dimension is scored from 1 to 3 and population-based preference weights are used to calculate the index score (maximum value 1) (Additional file 1). The instrument also includes a visual analogue scale (VAS) ranging from 0 to 100 (100 represents the best) for self-rating the health state. The baseline values were obtained during the patients ICU stay by interviewing either the patient himself or his proxy. For follow-up, the query was performed by a phone interview or a letter, depending on the practice in each centre. We calculated the EQ-5D index score and analysed it and the VAS score at baseline and after six months follow-up among patients who were reported to be alive at six months.

To compare septic and non-septic patients, we searched the patients with infection diagnosis by screening the APACHE III and ICD-10 diagnoses. We screened all patients for fulfilling the SIRS (systemic inflammatory response syndrome) -criteria [28]. We classified patients having sepsis if they had infection diagnosis and fulfilled at least two SIRS criteria, severe sepsis if they had sepsis and at least one non-cardiovascular organ failure defined by organ specific SOFA score 3 or 4 , and septic shock if they had sepsis and the cardiovascular SOFA score was 3 or 4 . We only included 
patients with emergency admission in the final analysis regarding sepsis in order to enhance the aptness of the retrospective sepsis classification.

We performed statistical analysis using SPSS Statistics 19.0 (SPSS Inc., Chicago, IL, USA). We report con-tinuous data as medians with interquartile range (IQR, $25^{\text {th }}$ to $75^{\text {th }}$ percentiles) and categorical data as percentages and count. We calculated $95 \%$ confidence intervals (CI) for the main outcome data. We used Mann-Whitney Utest to compare continuous variables and Chi-square test to compare categorical data. We compared repeated measurements (EQ-5D and VAS scores) with the Wilcoxon signed rank test. Reported $P$-values were twosided and significance was set at the 0.05 level.

We conducted a multiple logistic regression analysis to assess independent risk factors for hospital mortality of patients treated with RRT. We used a backwards elimination approach and a significance level of $<0.05$ for entry and $>0.10$ for stepwise removal. We entered the following variables: gender, admission type (surgical/ medical), time from hospital admission to ICU admission (days), SAPS II score, SOFA score and presence of severe sepsis. In the first model we found SOFA score not to be associated with mortality and, therefore, performed the second model where we replaced SOFA score with organ-specific variables: need for vasoactive drugs, need for mechanical ventilation, and serum creatinine. We tested the goodness of fit with the HosmerLemeshow C-statistics. We report odds ratios with $95 \%$ CI.

\section{Results}

We analysed the final cohort of 24,904 patients admitted to ICU from 1 January 2007 to 31 December 2008 (Figure 1). Of these patients, 1,686 received RRT due to AKI. The incidence of RRT-treated AKI was 6.8\% (95\% CI 6.5 to $7.1 \%$ ) among $\geq 15$-year-old general ICU patients, which corresponds to a yearly populationbased incidence of 19.2 per 100,000 (95\% CI 17.9 to 20.5) among $\geq 15$ year old inhabitants in Finland.

Characteristics of the patients are presented in Table 1. No significant difference in the age between patients treated with RRT (RRT patients) and patients who did not require RRT (non-RRT patients) existed $(P=0.173)$. The APACHE III diagnosis groups on admission are presented in Table 2 . We were able to classify $85.3 \%$ of the cohort according to RIFLE GFR criteria. Patients according to the maximum RIFLE class are presented in Table 3. Of the whole cohort, 5,662 of 21,251 patients (26.6\%; 95\% CI 26.0 to $27.2 \%$ ) had AKI according to RIFLE (R-F), and of these AKI patients, 1,120 (19.8\%) received RRT. Of all patients with AKI, 66.3\%, 79.2\% and $90.1 \%$ reached their maximum RIFLE-class during the first two, three and five days of ICU treatment, respectively. We identified 1,752 patients with RIFLE-F of whom 776 (44.3\%) received RRT. RRT was initiated within the first day in the ICU in $66.4 \%$ of the RRT patients. By days 2, 3 and 5 RRT was initiated for $83.3 \%$, 90.1\% and $95.1 \%$ of the RRT patients.

Outcome data and data on HRQoL as measured with the EQ-5D index and VAS scores are presented in Table 4, and the responses of the EQ-5D questionnaire at six months in Additional file 1. Hospital mortality of RRT patients stratified according to the timing of RRT initiation was $33.1 \%$ in patients with early (days 1 to 2 ) RRT, $39.8 \%$ with delayed (days 3 to 5 ) RRT, and $53.5 \%$ with late (from day 6 onwards) RRT $(P<0.001)$.

In multiple logistic regression analysis the time from hospital admission to ICU admission (days) and SAPS II score on admission (one point increments) were independently associated with increased risk for hospital mortality of RRT patients. The odds ratios (95\% CI) were 1.055 (1.029 to 1.081) $(P<0.001)$ per one day and 1.056 (1.048 to 1.065$)(P<0.001)$ per one SAPS II point, respectively. Higher serum creatinine and absence of severe sepsis were associated with a decreased risk for hospital death with odds ratios $(95 \% \mathrm{CI})$ of 0.998 (0.997 to 0.999$)$ per each micromol/l $(P<0.001)$ and 0.682 (0.528 to 0.881$)(P=0.003)$, respectively. The Hosmer-Lemeshow $\mathrm{C}$-statistics for the final model was $5.771(P=0.673)$.

Of the 1,553 RRT patients with emergency admission, 503 (32.4\%) had severe sepsis. Characteristics and outcome data of RRT patients with and without severe sepsis are presented in Additional file 2. Hospital mortality in RRT patients with severe sepsis was $44.5 \%$ (40.2 to $48.8 \%)$, and in non-RRT patients with sepsis or severe sepsis $19.3 \%$ (18.0 to $20.6 \%)(P<0.001)$.

\section{Discussion}

This large, retrospective multi-centre cohort study included all Finnish adult general ICU patients in a period of two years. We found that the population-based incidence of AKI treated with RRT was 19.2 per 100,000 among $\geq 15$-year-old inhabitants in Finland. During the study period, $6.8 \%$ of patients admitted to general ICUs were treated with RRT and $26.6 \%$ had AKI according to RIFLE classification. Hospital mortality of RRT patients was significantly higher compared to non-RRT patients, $35.0 \%$ vs. $15.5 \%$.

The previously reported population-based incidence of RRT-treated AKI varies from 8 to 30 per 100,000 [5-12]. In the nationwide prospective Australian study by Silvester et al. [5] the incidence of AKI treated with RRT in an ICU setting was 8 per 100,000 . Furthermore, RRT incidence in the United States in a study based on diagnosis and procedure codes in the Nationwide Inpatient Sample registry was 27 per 100,000 [11]. The study also 


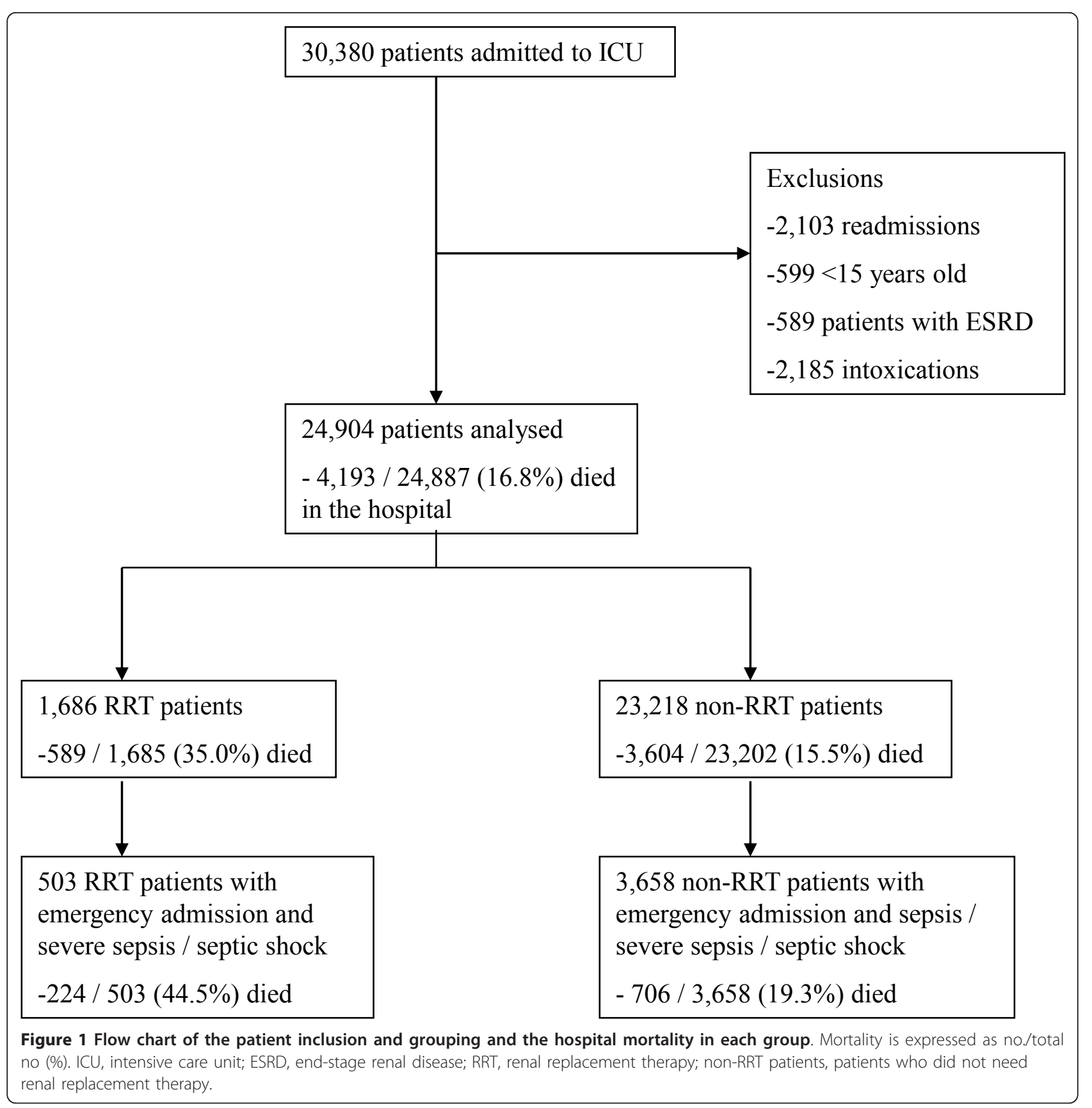

included patients with chronic kidney disease (CKD) [11]. Incidence of RRT-treated AKI was 28.6 per 100,000 in a prospective Scottish study conducted both in ICU and dialysis unit settings [10]. The populationbased incidence of RRT in our study was 19.2 per 100,000 , in broad agreement with the previous reports. In Finland, RRT administered due to AKI outside ICUs is rare, and, thus, lack of these data may have caused only a minor bias in the population-based incidence. The proportion of RRT-treated AKI in our study was in line with previous recent reports from other countries $[1,3,13,14]$.

The incidence of AKI defined by RIFLE has been reported to vary between 11 and $67 \%$ among ICU patients $[2,3,29]$. In the study by Joannidis et al. [29], the incidence of AKI defined by the GFR criteria alone was lower, $25 \%$ compared to $35 \%$, when urine output criteria also were considered. Since we were able to classify patients only on the basis of RIFLE GFR criteria, the proportion of AKI patients may be slightly 
Table 1 Characteristics of patients according to treatment with renal replacement therapy (RRT)

\begin{tabular}{|c|c|c|c|}
\hline Characteristic & $\begin{array}{l}\text { RRT } \\
N=1,686\end{array}$ & $\begin{array}{l}\text { Non-RRT } \\
N=23,218\end{array}$ & $P$-value \\
\hline Age - median (IQR) (yr) & 63 (52 to 72$)$ & 62 (50 to 73$)$ & 0.173 \\
\hline Male gender - no./total no. (\%) & $1,143 / 1,685(67.8 \%)$ & $14,641 / 23,200(63.1 \%)$ & $<0.001$ \\
\hline SAPS II score - median (IQR) & $48(37$ to 62$)$ & $33(23$ to 46$)$ & $<0.001$ \\
\hline SOFA (1.d) score - median (IQR) & $10(7$ to 13$)$ & 6 (3 to 8$)$ & $<0.001$ \\
\hline Mean daily TISS score - median (IQR) & 36.4 (29.7 to 43.2$)$ & 28.7 (22.4 to 35.0$)$ & $<0.001$ \\
\hline Emergency admission - no./total no. (\%) & $1,558 / 1,684(92.5 \%)$ & $19,122 / 23,202(82.4 \%)$ & $<0.001$ \\
\hline Surgical admission- no./total no. (\%) & $410 / 1,685(24.3 \%)$ & $9,426 / 23,208(40.6 \%)$ & $<0.001$ \\
\hline Sepsis/severe sepsis - no./total no.(\%) & $510 / 1,681(30.3 \%)$ & $3,753 / 23,101(16.2 \%)$ & $<0.001$ \\
\hline Mechanical ventilation - no./total no. (\%) & $1,014 / 1,642(61.8 \%)$ & $11,116 / 22,409$ (49.6\%) & $<0.001$ \\
\hline Vasoactives-no./total no. (\%) & $1,067 / 1,671(63.9 \%)$ & $9,556 / 23,175$ (41.2\%) & $<0.001$ \\
\hline Creatinine - median (IQR) (micromol/L) & $210(119 \text { to } 352)^{*}$ & $72(56$ to 101$)+$ & $<0.001$ \\
\hline Urine output - median (IQR) (mL/d) & 829 (232 to 1,947$)$ & $2,355(1,555$ to 3,390$)$ & $<0.001$ \\
\hline
\end{tabular}

IQR, Interquartile range ( $25^{\text {th }}$ to $75^{\text {th }}$ percentiles); SAPS, Simplified Acute Physiology Score; SOFA, Sequential Organ Failure Assessment; TISS, Therapeutic Intervention Scoring System. * Data missing for $5 \%$ of cases. +Data missing for $7 \%$ of cases.

underestimated, and may explain along with the early initiation of RRT why $16 \%$ of the RRT patients did not fill the RIFLE GFR criteria. Interestingly, the mortality of RIFLE-F patients with or without RRT did not differ, and RRT patients with RIFLE-I or RIFLE-R had higher mortality rates than RIFLE-F RRT patients. With urine

Table 2 The APACHE (Acute Physiology and Chronic Health Evaluation) III diagnostic groups of the patients

\begin{tabular}{|c|c|c|}
\hline & RRT & Non-RRT \\
\hline Total no. of patients* & 1,685 & 23,208 \\
\hline Non-operative & $1,275(75.7 \%)$ & $13,782(59.4 \%)$ \\
\hline Cardiovascular & $153(9.1 \%)$ & $3,111(13.4 \%)$ \\
\hline Gastrointestinal & $149(8.8 \%)$ & $1,338(5.8 \%)$ \\
\hline Hematological & $22(1.3 \%)$ & $65(0.3 \%)$ \\
\hline Metabolic & $102(6.1 \%)$ & $891(3.8 \%)$ \\
\hline Neurological & $74(4.4 \%)$ & $2,423(10.4 \%)$ \\
\hline Renal & $257(15.3 \%)$ & $159(0.7 \%)$ \\
\hline Respiratory & $146(8.7 \%)$ & $2,572(11.1 \%)$ \\
\hline Sepsis & $284(16.9 \%)$ & $1,110(4.8 \%)$ \\
\hline Trauma & $25(1.5 \%)$ & $1,115(4.8 \%)$ \\
\hline Other & $44(2.6 \%)$ & $661(2.8 \%)$ \\
\hline Missing & $19(1.1 \%)$ & $337(1.5 \%)$ \\
\hline Postoperative & $410(24.3 \%)$ & $9,426(40.6 \%)$ \\
\hline Cardiovascular & 177 (10.5\%) & $2,947(12.7 \%)$ \\
\hline Gastrointestinal & 137 (8.1\%) & $2,290(9.9 \%)$ \\
\hline Gynecological & $8(0.5 \%)$ & $313(1.3 \%)$ \\
\hline Neurological & $29(1.7 \%)$ & $2,060(8.9 \%)$ \\
\hline Orthopedic & $7(0.4 \%)$ & $391(1.7 \%)$ \\
\hline Renal & $12(0.7 \%)$ & $224(1.0 \%)$ \\
\hline Respiratory & $13(0.8 \%)$ & $563(2.4 \%)$ \\
\hline Trauma & $11(0.7 \%)$ & $419(1.8 \%)$ \\
\hline Missing & $16(0.9 \%)$ & 219 (0.9\%) \\
\hline
\end{tabular}

RRT; renal replacement therapy, non-RRT; patients without renal replacement therapy * Data on APACHE III diagnosis group were missing for one RRT patient and 10 non-RRT patients. output criteria these RIFLE-R and RIFLE-I patients might have reached RIFLE-F class. Previously, it has been reported that 14 to $30 \%$ of RIFLE-F patients had received RRT [2,3]. In our study, the proportion was greater, although the overall population-based incidence of RRT corresponded with previous studies.

In this study, the hospital mortality of RRT patients with corresponding characteristics and disease severity (SAPS II has ranged from 45 to 48 in studies with reported values $[13,17,18]$ ) was lower than in previous studies with mortality rates between 44 and $64 \%$ [13,15-19]. The lowest hospital mortality rates have been from 44 [15] to $47 \%$ [5]. In both studies half of the patients had severe sepsis [5,15]. Silvester et al. [5] reported a mean SAPS II score of 55, which equals the score of the RRT patients with severe sepsis in our study, whose hospital mortality was $44.5 \%$. Waikar et al. [11] reported hospital mortality of RRT-treated patients to be only $28.1 \%$, but the study included also patients with CKD. A third of RRT patients in our study had severe sepsis compared to half in previous studies with higher hospital mortality rates [16-18]. A smaller proportion of patients with severe sepsis may have contributed to the lower mortality rate in our study. However, RRT patients with severe sepsis had a lower mortality rate compared to previous reports [16-18]. Hospital mortality of septic AKI patients (of whom $70 \%$ received RRT) with corresponding severity of disease has been reported to be 70\% [30]. In our cohort, RRT was initiated earlier compared to the study by Bagshaw et al. [31]. Tendency to initiate RRT early in Finland offers one possible explanation for better survival. Delannoy et al. [21] reported the sixmonth mortality of RRT-treated AKI patients with median SAPS II score of 63 to be $62 \%$. In our study, the most severely ill patients (RRT patients with severe 
Table 3 Patients classified according to RIFLE (Risk, Injury, Failure) glomerular filtration rate criteria

\begin{tabular}{lllll}
\hline & All $(\boldsymbol{N}=\mathbf{2 4 , 9 0 4})$ & RRT $(\boldsymbol{N}=\mathbf{1 , 6 8 6})$ & RRT, before* & Non-RRT $(\boldsymbol{N}=\mathbf{2 3 , 2 1 8})$ \\
\hline No AKI & $15,589(73.4 \%)$ & $219(16.4 \%)$ & $147(19.8 \%)$ & $15,370(77.2 \%)$ \\
Risk & $2,198(10.3 \%)$ & $100(7.5 \%)$ & $62(8.4 \%)$ & $2,098(10.5 \%)$ \\
Injury & $1,712(8.1 \%)$ & $244(18.2 \%)$ & $150(20.2 \%)$ & $1,468(7.4 \%)$ \\
Failure & $1,752(8.2 \%)$ & $776(58.0 \%)$ & $383(51.6 \%)$ & $976(4.9 \%)$ \\
No data & $3,653(14.7 \%)$ & $347(20.6 \%)$ & $944(56 \%)$ & $3,306(14.2 \%)$ \\
\hline
\end{tabular}

AKI, Acute kidney injury; RRT; renal replacement therapy, non-RRT; patients without renal replacement therapy *RIFLE class before the initiation of RRT

sepsis) had slightly lower SAPS II scores and a sixmonth mortality rate of $59 \%$.

The SAPS II based SMR of RRT patients was 0.76 in our study. Previously, Uchino et al. [17] have reported a SMR of 1.38 among patients receiving continuous RRT. Silvester et al. [5] reported a SAPS II predicted mortality of $51.2 \%$ with an observed mortality of $46.8 \%$ and in the study by Metnitz et al. [13] the SAPS II predicted and observed mortality were $44.7 \%$ and $62.8 \%$, respectively. The SMRs yielded from both of these studies remain higher than in our study. It has been discussed that SAPS II may underestimate the mortality of patients with AKI [1], while our results imply that SAPS II generally overestimates the mortality of both RRT and nonRRT patients. Given the lower SMR of RRT patients compared to non-RRT patients, the treatment of RRT patients may not have improved as much as the treatment of non-RRT patients since the validation of SAPS II scoring system.

As we found in the multiple regression analysis, longer time from hospital admission to ICU among patients receiving continuous RRT [17] and high SAPS II score among AKI patients have been associated with increased mortality, while the absence of severe sepsis has been associated with better survival [1]. We found an association with higher creati-nine on ICU admission and decreased risk for mortality, potentially reflecting that patients with higher creatinine had more often isolated AKI. Higher creatinine on the day of RRT initiation has been associated with decreased mortality [31,32], which may be explained by better nutritional status reflecting better overall health status [31,32] or underlying CKD and an acute-on-chronic kidney injury with different prognosis [31]. Lower creatinine and worse outcome may account for volume overload known to be independently associated with increased mortality [31,32].

We were able to obtain the six-month follow-up EQ$5 \mathrm{D}$ index score only from $44 \%$ of RRT patients, which may have caused bias. Our cohort of 313 patients, however, is the second largest to our knowledge of RRTtreated patients with HRQoL data. In addition, we compared the HRQoL of RRT patients to non-RRT patients.

Table 4 Outcome of patients according to treatment with renal replacement therapy (RRT)

\begin{tabular}{|c|c|c|c|}
\hline & $\begin{array}{l}\text { RRT } \\
N=1,686\end{array}$ & $\begin{array}{l}\text { Non-RRT } \\
N=23,218\end{array}$ & $P$-value \\
\hline ICU stay - median (IQR) days & $5.2(1.9$ to 10.8$)$ & 1.5 (0.9 to 3.2$)$ & $<0.001$ \\
\hline Hospital stay - median (IQR) days & $16(8$ to 29$)$ & $9(5$ to 16$)$ & $<0.001$ \\
\hline Treatment restricted -no./total no. (\%) & $388 / 1,533(25.3 \%)$ & $2,665 / 21,339(12.5 \%)$ & $<0.001$ \\
\hline Hospital mortality -no./total no. $(\%(95 \% \mathrm{Cl}))$ & $589 / 1,685(35.0 \%(32.7$ to $37.3 \%))$ & $3,604 / 23,202(15.5 \%(15.0$ to $16.0 \%))$ & $<0.001$ \\
\hline Hospital mortality -No AKI according to RIFLE -no./total no. (\%) & $40 / 219(18.3 \%)$ & $1,573 / 15,364(10.2 \%)$ & $<0.001$ \\
\hline Hospital mortality -RIFLE -Risk -no./total no. (\%) & $40 / 100(40 \%)$ & $480 / 2,095$ (22.9\%) & $<0.001$ \\
\hline Hospital mortality -RIFLE -Injury -no./total no. (\%) & $128 / 244(52.5 \%)$ & $430 / 1,468(29.3 \%)$ & $<0.001$ \\
\hline Hospital mortality -RIFLE -Failure -no./total no. (\%) & $245 / 776(31.6 \%)$ & $326 / 976(33.4 \%)$ & 0.417 \\
\hline SAPS II based SMR - $(95 \% \mathrm{Cl})$ & $0.76(0.70$ to 0.82$)$ & 0.61 (0.59 to 0.63$)$ & \\
\hline Six-month mortality -no./total no. $(\%(95 \% \mathrm{Cl}))$ & $699 / 1,415(49.4 \%(46.8$ to $52.0 \%))$ & $5,101 / 18,367(27.8 \%(27.2$ to $28.5 \%))$ & $<0.001$ \\
\hline EQ-5D index at baseline - median (IQR) - no./total no. (\%) & $0.68(0.49$ to 1.0$) 431 / 716(60.2 \%)$ & 0.69 (0.53 to 1.0$) 7,487 / 13,266(56.4 \%)$ & 0.004 \\
\hline EQ-5D index at six months - median (IQR) - no./total no. (\%) & $\begin{array}{l}0.63(0.49 \text { to } 0.79) \\
313 / 716(43.7 \%)\end{array}$ & $\begin{array}{l}0.68(0.52 \text { to } 1.0) \\
5,415 / 13,266(40.8 \%)\end{array}$ & 0.015 \\
\hline VAS at baseline - median (IQR) - no./total no. (\%) & $\begin{array}{l}60(40 \text { to } 80) \\
223 / 716(31.1 \%)\end{array}$ & $\begin{array}{l}70(50 \text { to } 80) \\
4,505 / 13,266(34.0 \%)\end{array}$ & 0.009 \\
\hline VAS at six months - median (IQR) - no./total no. (\%) & $\begin{array}{l}70(50 \text { to } 80) \\
274 / 716(38.3 \%)\end{array}$ & 70 (55 to 85$) 4,841 / 13,266$ (36.5\%) & 0.059 \\
\hline
\end{tabular}

Quality of life is measured with the EuroQol (EQ-5D) index and with the visual analogue scale (VAS) score. AKl; Acute kidney injury, IQR; interquartile range (25th to 75 th percentiles), RIFLE, Risk, Injury, Failure -classification; SAPS, Simplified Acute Physiology Score; SMR, standardised mortality ratio. Treatment restrictions include: 1) no resuscitation, 2) no increase in the intensity of treatment, 3) treatment withdrawal. 
Among cancer patients, 0.06 to 0.08 has been considered as a minimally important clinical difference in the EQ-5D index score and 7 for the VAS score [33]. Several previous studies have reported lower HRQoL among RRT patients compared to matched general population [20,21]. Morsch et al. [34] found that younger and less severely ill RRT-treated patients had better HRQoL as measured with the SF-36 instrument than older patients with long hospital stay. Johansen et al. [35] reported an extremely low HRQoL among 60day survivors after RRT. We found no clinically significant difference in EQ-5D score between RRT and nonRRT patients after six months follow-up. Regarding the five dimensions of the EQ-5D index, the groups did not differ in suffering from pain or anxiety, and differences in scores for mobility, self-care and usual activities were small. In addition, the VAS score reflecting the patients own perception of health at six months of RRT patients corresponded with the score of non-RRT patients and the earlier reported score of general population [20].

There are some limitations to our study. First, the data were prospectively collected as a routine set of all ICU admissions and, therefore, not addressed to answer specific questions regarding the received RRT. Accordingly, we lack information on the modality and dose of RRT. Second, we were unable to apply the urine output criteria of RIFLE classifica-tion and obtain a true baseline creatinine. Third, the six-month mortality rate was available only from $80 \%$ of the patients. However, our cohort is to the best of our knowledge the largest population reporting six-month mortality data of RRT-treated AKI among critically ill patients.

\section{Conclusions}

In conclusion, the population-based incidence of AKI treated with RRT was 19.2 per 100,000 . Of all ICU patients, $6.8 \%$ received RRT and $26.6 \%$ had AKI according to RIFLE classification. In this unselected population of general ICU patients, the hospital and six-month mortality rates were lower than previously reported for ICU-treated RRT patients.

\section{Key messages}

- Population-based incidence of RRT-treated AKI was 19.2 per 100,000 in Finland and $6.8 \%$ of all adult general ICU-patients.

- Hospital and six-month mortality of patients treated with RRT were $35.0 \%$ and $49.4 \%$, respec-tively.

- Patients treated with RRT perceived their health related quality of life after six-months follow-up as good as patients treated without RRT and general population.

\section{Additional material}

Additional file 1: EQ-5D health-related quality of life in critically ill patients with renal replacement therapy (RRT) at six months.

Additional file 2: Characteristics and outcome of critically ill emergency patients treated with renal re-placement therapy according to presence or absence of severe sepsis or septic shock

\section{Abbreviations}

ADQI: Acute Dialysis Quality Initiative; AKI: acute kidney injury; APACHE: Acute Physiology and Chronic Health Evaluation; CKD: chronic kidney disease; ESRD: end-stage renal disease; EQ-5D index: EuroQol-instrument for analysing health related quality of life; GFR: glomerular filtration rate; HRQoL: health related quality of life; ICD-10: International Classification of Diseases, $10^{\text {th }}$ revision; LOS: length of stay; MDRD: Modification in Diet in Renal Disease; non-RRT patients: patients who were not treated with renal replacement therapy; RRT: renal replacement therapy; RIFLE: Risk, Injury, Failure -classification; SAPS: Simplified Acute Physiology Score; SOFA: Sequential Organ Failure Assessment; TISS: Therapeutic Intervention Scoring System; SMR: standardised mortality ratio; VAS: visual analogue scale

\section{Acknowledgements}

We thank FICC for the permission to use the data in this study and the FICC member ICUs for collecting the data. We thank Petteri Mussalo, Tieto Healthcare \& Welfare Ltd, for his help in retrieving the data from the database of the FICC. The preliminary results of this study were presented as a conference abstract at the 24th European Society of Intensive Care Medicine Congress; October 5, 2011, Berlin, Germany. STV has received a grant from the Finnish Society of Anaesthesiologists. KMK has received a grant for Clinical Research Career from the Academy of Finland. The study was supported by EVO grant TYH 2010109 from Helsinki University Hospital. Hospitals participating in the Finnish Intensive Care Consortium (in alphabetical order):

Helsinki University Central Hospital, Helsinki; Jorvi Hospital, Espoo/Helsinki; Kainuu Central Hospital, Kajaani; Kanta-Häme Central Hospital, Hämeenlinna; Keski-Pohjanmaa Central Hospital, Kokkola; Keski-Suomi Central Hospital, Jyväskylä; Kuopio University Hospital, Kuopio; Kymenlaakso Central Hospital, Kotka; Lappi Central Hospital, Rovaniemi; Länsi-Pohja Central Hospital, Kemi; Mikkeli Central Hospital, Mikkeli; North Karelia Central Hospital, Joensuu; Oulu University Hospital, Oulu; Päijät-Häme Central Hospital, Lahti; Satakunta Central Hospital, Pori; Savonlinna Central Hospital, Savonlinna; Seinäjoki Central Hospital, Seinäjoki;

South Karelia Central Hospital, Lappeenranta; Tampere University Hospital, Tampere; Turku University Central Hospital, Turku; Vaasa Central Hospital, Vaasa

\section{Author details}

${ }^{1}$ Intensive Care Units, Division of Anaesthesia and Intensive Care Medicine, Department of Surgery, Helsinki University Central Hospital, Box 340, 00029 HUS, Finland. '2Department of Intensive Care, North Karelia Central Hospital, Tikkamäentie 16, 80210, Joensuu, Finland.

\section{Authors' contributions}

STV carried out the data analysis and drafted the manuscript. VP participated in designing the study and critically revising the manuscript. MR participated in the data analysis and critically revised the manuscript. KMK conceived the study, participated in its design and helped to draft the manuscript. All authors read and approved the final manuscript.

\section{Competing interests}

The authors declare that they have no competing interests.

Received: 22 September 2011 Revised: 15 December 2011

Accepted: 20 January 2012 Published: 20 January 2012 


\section{References}

1. Uchino S, Kellum JA, Bellomo R, Doig GS, Morimatsu H, Morgera S, Schetz M, Tan I, Bouman C, Macedo E, Gibney N, Tolwani A, Ronco C: Beginning and Ending Supportive Therapy for the Kidney (BEST Kidney) Investigators: Acute renal failure in critically ill patients: a multinational, multicenter study. JAMA 2005, 294:813-818

2. Cruz DN, Bolgan I, Perazella MA, Bonello M, de Cal M, Corradi V, Polanco N, Ocampo C, Nalesso F, Piccinni P, Ronco C: North East Italian Prospective Hospital Renal Outcome Survey on Acute Kidney Injury (NEiPHROS-AKI) Investigators: North East Italian Prospective Hospital Renal Outcome Survey on Acute Kidney Injury (NEiPHROS-AKI): targeting the problem with the RIFLE Criteria. Clin J Am Soc Nephrol 2007, 2:418-425.

3. Hoste EA, Clermont G, Kersten A, Venkataraman R, Angus DC, De Bacquer D, Kellum JA: RIFLE criteria for acute kidney injury are associated with hospital mortality in critically ill patients: a cohort analysis. Crit Care 2006, 10:R73.

4. Bellomo R, Ronco C, Kellum JA, Mehta RL, Palevsky P: Acute Dialysis Quality Initiative workgroup: Acute renal failure - definition, outcome measures, animal models, fluid therapy and information technology needs: the Second International Consensus Conference of the Acute Dialysis Quality Initiative (ADQI) Group. Crit Care 2004, 8:R204-212.

5. Silvester W, Bellomo R, Cole L: Epidemiology, management, and outcome of severe acute renal failure of critical illness in Australia. Crit Care Med 2001, 29:1910-1915.

6. Korkeila M, Ruokonen E, Takala J: Costs of care, long-term prognosis and quality of life in patients requiring renal replacement therapy during intensive care. Intensive Care Med 2000, 26:1824-1831.

7. Bagshaw SM, Laupland KB, Doig CJ, Mortis G, Fick GH, Mucenski M, Godinez-Luna T, Svenson LW, Rosenal T: Prognosis for long-term survival and renal recovery in critically ill patients with severe acute renal failure: a population-based study. Crit Care 2005, 9:R700-9.

8. Yasuda H, Kato A, Fujigaki Y, Hishida A: Shizuoka Kidney Disease Study Group: Incidence and clinical outcomes of acute kidney injury requiring renal replacement therapy in Japan. Ther Apher Dial 2010, 14:541-546.

9. Metcalfe W, Simpson M, Khan IH, Prescott GJ, Simpson K, Smith WC MacLeod AM: Scottish Renal Registry: Acute renal failure requiring renal replacement therapy: incidence and outcome. QJM 2002, 95:579-583.

10. Prescott GJ, Metcalfe W, Baharani J, Khan IH, Simpson K, Smith WC, MacLeod AM: A prospective national study of acute renal failure treated with RRT: incidence, aetiology and outcomes. Nephrol Dial Transplant 2007, 22:2513-2519.

11. Waikar SS, Curhan GC, Wald R, McCarthy EP, Chertow GM: Declining mortality in patients with acute renal failure, 1988 to 2002. J Am SoC Nephrol 2006, 17:1143-1150

12. Hsu CY, McCulloch CE, Fan D, Ordonez JD, Chertow GM, Go AS: Community-based incidence of acute renal failure. Kidney Int 2007, 72:208-212.

13. Metnitz PG, Krenn CG, Steltzer H, Lang T, Ploder J, Lenz K, Le Gall JR, Druml W: Effect of acute renal failure requiring renal replacement therapy on outcome in critically ill patients. Crit Care Med 2002, 30:2051-2058

14. Piccinni P, Cruz DN, Gramaticopolo S, Garzotto F, Dal Santo M, Aneloni G, Rocco M, Alessandri E, Giunta F, Michetti V, lannuzzi M, Belluomo Anello C, Brienza N, Carlini M, Pelaia P, Gabbanelli V, Ronco C: Prospective multicenter study on epidemiology of acute kidney injury in the ICU: a critical care nephrology Italian collaborative effort (NEFROINT). Minerva Anestesiol 2011, 77:1072-1083.

15. RENAL Replacement Therapy Study Investigators, Bellomo R, Cass A, Cole L, Finfer S, Gallagher M, Lo S, McArthur C, McGuinness S, Myburgh J, Norton R, Scheinkestel C, Su S: Intensity of continuous renal-replacement therapy in critically ill patients. N Engl J Med 2009, 361:1627-1638.

16. VA/NIH Acute Renal Failure Trial Network, Palevsky PM, Zhang JH, O'Connor TZ, Chertow GM, Crowley ST, Choudhury D, Finkel K, Kellum JA, Paganini E, Schein RM, Smith MW, Swanson KM, Thompson BT, Vijayan A, Watnick S, Star RA, Peduzzi P: Intensity of renal support in critically ill patients with acute kidney injury. N Engl J Med 2008, 359:7-20.

17. Uchino S, Bellomo R, Morimatsu H, Morgera S, Schetz M, Tan I, Bouman C, Macedo E, Gibney N, Tolwani A, Oudemans-van Straaten H, Ronco C, Kellum JA: Continuous renal replacement therapy: a worldwide practice survey. The beginning and ending supportive therapy for the kidney ( $B$. E.S.T. kidney) investigators. Intensive Care Med 2007, 33:1563-1570.
18. De Corte W, Vanholder R, Dhondt AW, De Waele JJ, Decruyenaere J, Danneels C, Claus S, Hoste EA: Serum urea concentration is probably not related to outcome in ICU patients with AKI and renal replacement therapy. Nephrol Dial Transplant 2011, 26:3211-3218.

19. Bagshaw SM, Mortis G, Doig CJ, Godinez-Luna T, Fick GH, Laupland KB: Oneyear mortality in critically ill patients by severity of kidney dysfunction: a population-based assessment. Am J Kidney Dis 2006, 48:402-409.

20. Åhlström A, Tallgren M, Peltonen S, Räsänen P, Pettilä V: Survival and quality of life of patients requiring acute renal replacement therapy. Intensive Care Med 2005, 31:1222-1228.

21. Delannoy B, Floccard B, Thiolliere F, Kaaki M, Badet M, Rosselli S, Ber CE, Saez A, Flandreau G, Guerin C: Six-month outcome in acute kidney injury requiring renal replacement therapy in the ICU: a multicentre prospective study. Intensive Care Med 2009, 35:1907-1915.

22. Le Gall JR, Lemeshow S, Saulnier F: A new Simplified Acute Physiology Score (SAPS II) based on a European/North American multicenter study. JAMA 1993, 270:2957-2963.

23. Vincent IL, de Mendonca A, Cantraine F, Moreno R, Takala J, Suter PM, Sprung CL, Colardyn F, Blecher S: Use of the SOFA score to assess the incidence of organ dysfunction/failure in intensive care units: results of a multicenter, prospective study. Working group on "sepsis-related problems" of the European Society of Intensive Care Medicine. Crit Care Med 1998, 26:1793-1800.

24. Keene AR, Cullen DJ: Therapeutic Intervention Scoring System: update 1983. Crit Care Med 1983, 11:1-3.

25. National Kidney Foundation: K/DOQI clinical practice guidelines for chronic kidney disease: evaluation, classification, and stratification. Am J Kidney Dis 2002, 39:51-266.

26. Brooks R: EuroQol: the current state of play. Health Policy 1996, 37:53-72.

27. Wu A, Gao F: Long-term outcomes in survivors from critical illness. Anaesthesia 2004, 59:1049-1052

28. Bone RC, Balk RA, Cerra FB, Dellinger RP, Fein AM, Knaus WA, Schein RM, Sibbald WJ: Definitions for sepsis and organ failure and guidelines for the use of innovative therapies in sepsis. The ACCP/SCCM Consensus Conference Committee. American College of Chest Physicians/Society of Critical Care Medicine. Chest 1992, 101:1644-1655.

29. Joannidis M, Metnitz B, Bauer P, Schusterschitz N, Moreno R, Druml W Metnitz PG: Acute kidney injury in critically ill patients classified by AKIN versus RIFLE using the SAPS 3 database. Intensive Care Med 2009, 35:1692-1702.

30. Bagshaw SM, Uchino S, Bellomo R, Morimatsu H, Morgera S, Schetz M, Tan I, Bouman C, Macedo E, Gibney N, Tolwani A, Oudemans-van Straaten HM, Ronco C, Kellum JA: Beginning and Ending Supportive Therapy for the Kidney (BEST Kidney) Investigators: Septic acute kidney injury in critically ill patients: clinical characteristics and outcomes. Clin J Am Soc Nephrol 2007, 2:431-439.

31. Bagshaw SM, Uchino S, Bellomo R, Morimatsu H, Morgera S, Schetz M, Tan I, Bouman C, Macedo E, Gibney N, Tolwani A, Oudemans-van Straaten HM, Ronco C, Kellum JA: Beginning and Ending Supportive Therapy for the Kidney (BEST Kidney) Investigators: Timing of renal replacement therapy and clinical outcomes in critically ill pa-tients with severe acute kidney injury. J Crit Care 2009, 24:129-140.

32. Ostermann M, Chang RW: Correlation between parameters at initiation of renal replacement therapy and outcome in patients with acute kidney injury. Crit Care 2009, 13:R175.

33. Pickard AS, Neary MP, Cella D: Estimation of minimally important differences in EQ-5D utility and VAS scores in cancer. Health Qual Life Outcomes 2007, 5:70.

34. Morsch C, Thomé FS, Balbinotto A, Guimaraes JF, Barros EG: Health-related quality of life and dialysis dependence in critically ill patient survivors of acute kidney injury. Ren Fail 2011, 33:949-956.

35. Johansen KL, Smith MW, Unruh ML, Siroka AM, O'Connor TZ, Palevsky PM: VA/NIH Acute Renal Failure Trial Network: Predictors of health utility among 60-day survivors of acute kidney injury in the Veterans Affairs/ National Institutes of Health Acute Renal Failure Trial Network Study. Clin J Am Soc Nephrol 2010, 5:1366-1372.

doi:10.1186/cc11158

Cite this article as: Vaara et al:: Population-based incidence, mortality and quality of life in critically ill patients treated with renal replacement therapy: a nationwide retrospective cohort study in finnish intensive care units. Critical Care 2012 16:R13. 